\title{
Probiotics and Achyranthes bidentata Polysaccharides Improve Growth Performance via Promoting Intestinal Nutrient Utilization and Enhancing Immune Function of Weaned Pigs
}

\author{
Gaifeng Hou ${ }^{1,2}$, Wei Peng ${ }^{2}$, Liangkai Wei ${ }^{2}$, Rui Li ${ }^{1, *}$, Xingguo Huang ${ }^{2}$ and Yulong Yin ${ }^{1,2}$ \\ 1 Key Laboratory of Agro-Ecological Processes in Subtropical Region, Hunan Provincial Key Laboratory of \\ Animal Nutritional Physiology and Metabolic Process, Hunan Research Center of Livestock and Poultry \\ Sciences, South Central Experimental Station of Animal Nutrition and Feed Science in the Ministry of \\ Agriculture, National Engineering Laboratory for Poultry Breeding Pollution Control and Resource \\ Technology, Institute of Subtropical Agriculture, Chinese Academy of Sciences, Changsha 410125, China; \\ hougf521@163.com (G.H.); yinyulong@isa.ac.cn (Y.Y.) \\ 2 College of Animal Science and Technology, Hunan Agricultural University, Changsha 410128, China; \\ pengwei20210730@163.com (W.P.); wlk20210730@163.com (L.W.); hxg68989@hunau.edu.cn (X.H.) \\ * Correspondence: lirui@isa.ac.cn; Tel.: +86-0731-8461-9750
}

\section{check for} updates

Citation: Hou, G.; Peng, W.; Wei, L.; Li, R.; Huang, X.; Yin, Y. Probiotics and Achyranthes bidentata Polysaccharides Improve Growth Performance via Promoting Intestinal Nutrient Utilization and Enhancing Immune Function of Weaned Pigs. Animals 2021, 11, 2617. https:// doi.org/10.3390/ani11092617

Academic Editor:

Małgorzata Kasprowicz-Potocka

Received: 28 July 2021

Accepted: 3 September 2021

Published: 7 September 2021

Publisher's Note: MDPI stays neutral with regard to jurisdictional claims in published maps and institutional affiliations.

Copyright: (c) 2021 by the authors. Licensee MDPI, Basel, Switzerland. This article is an open access article distributed under the terms and conditions of the Creative Commons Attribution (CC BY) license (https:// creativecommons.org/licenses/by/ $4.0 /)$.
Simple Summary: It is frequent to see that in-feed antibiotics are added to piglets diets because of their enteric problems after weaning. However, in-feed antibiotics have been forbidden to used in livestock production since 1 July 2020 in China. Therefore, it is urgent to develop some promising alternatives to in-feed antibiotics. Probiotics and plant extracts are considered to be the potential replacements, which have been studied or applied in animal production. In our study, we found that probiotic or Achyranthes bidentata polysaccharides used alone or in combination, the combination augmenting the positive effect more than the independent supplement, could improve piglets' growth performance via promoting intestinal nutrient digestion and absorption and enhancing immune funtion, and the beneficial role was comparable to that of the selected in-feed antibiotics.

Abstract: The experiment aimed to investigate the effects of probiotics and Achyranthes bidentata polysaccharides on the growth performance, nutrients digestibility, and immune function of weaned pigs. One hundred and twenty weaned pigs (about $7 \mathrm{~kg} \mathrm{BW}, 23 \pm 2 \mathrm{~d}$ ) were allotted to five dietary treatments (CON: antibiotics-free basal diet; ANT: CON + antibiotics; PRO: CON + probiotics; ABPS: $\mathrm{CON}+$ Achyranthes bidentata polysaccharides; P-ABPS: $\mathrm{PRO}+\mathrm{ABPS})$ for a 28-day trial. Compared with CON, pigs in ANT, PRO, ABPS, and P-ABPS had greater $(p<0.05)$ ADG, ATTD of CP and GE, serum ALB, IgA and IL-2, duodenal intraepithelial lymphocyte, ileal VH and jejunal mucosa sIgA, but lower $(p<0.05)$ fecal scores, serum BUN, and IL-1 $\beta$. Meanwhile, ANT, PRO, ABPS, and P-ABPS exhibited similar beneficial roles on growth performance, nutrients digestibility, serum parameters, and immune function. Interestingly, P-ABPS effects were similar to those obtained with ANT rather than with PRO or ABPS. In conclusion, Dietary PRO or ABPS used alone or in combination (P-ABPS), the combination augmenting the positive effect more than the independent supplement, could improve piglets' growth performance via promoting intestinal nutrient digestion and absorption and enhancing immune function, indicating it had the potential to act as an alternative to in-feed antibiotics used in piglet diets.

Keywords: probiotics; Achyranthes bidentata polysaccharides; growth performance; immune; weaned pigs

\section{Introduction}

Early weaning can increase the pigs weaned per sow per year (PSY) and improve the utilization efficiency of pigsties, which has been commonly applied in the modern swine industry all over the world. However, early weaning might result in piglet anorexia, 
growth retardation, severe enteric infections, or even death, due to shorter suckling period as well as abrupt changes in dietary and social environment in comparison with the natural weaning [1,2]. Traditionally, adding in-feed antibiotics to the piglet diets can effectively control intestinal diseases and promote growth. However, the ban on the use of in-feed antibiotics in livestock feed has been proposed and gradually put into practice worldwide because of their side effects on human health and the environment [3]. Therefore, finding safe and efficient antibiotic alternatives for young pigs has become a global focus.

Probiotics known as an in-feed antibiotics replacement have been widely used in piglet diets, which exert beneficial effects on regulation of intestinal microflora, control of enteric pathogenic bacteria, ameliorating gut health, reducing diarrhea, and improving growth performance [4,5]. Additionally, traditional Chinese herbal medicine is also a potential substitute to antibiotics. Previous studies have confirmed that polysaccharides derived from the Chinese herb ox knee Achyranthes bidentata (ABPS) possesses immunomodulatory functions, and can be used as a diet additive for weanling piglets to enhance piglet growth [6,7].

Based on the above, we hypothesized that probiotics in combination with ABPS would improve piglets' growth and its beneficial effect would be better than when used alone, and equal or superior to in-feed antibiotics. To test the hypothesis, growth performance, nutrients digestibility, serum biochemical and immune indexes, serum cytokines, intestinal morphology, and immune function of piglets were determined.

\section{Materials and Methods}

All animal care, handling, and surgical techniques followed protocols approved by the Animal Care and Use Committee of the Institute of Subtropical Agriculture, Chinese Academy of Sciences (IACUC\#201302).

The chlortetracycline hydrochloride belongs to antibiotics growth promoters (AGP), which is provided by the Chia Tai Group (Changsha, China) and its available content is 15\%. The probiotics used in this study were made by our lab and the product has been patented in China [8]. The product mainly included Lactobacillus delbrueckii, Bacillus subtilis and Saccharomyces paradoxus, and the total colony-forming units (CFU) were $1.0 \times 10^{8} \mathrm{CFU} / \mathrm{g}$. Achyranthes bidentata Polysaccharides (ABPS) were purchased from Wuhan Dongkang Source Technology Co., Ltd. (Wuhan, China), the products are prepared by an extraction and drying process, and its purity (99\%) was measured by HPLC.

\subsection{Animals, Experimental Design, Diets and Management}

A total of 120 crossbred (Landrace $\times$ Large White), weaned pigs with an initial body weight of about $7 \mathrm{~kg}(23 \pm 2 \mathrm{~d})$ were randomly assigned to 1 of 5 diets: (1) non-antibiotic basal diet (CON); (2) basal diets $+75 \mathrm{mg} / \mathrm{kg}$ chlortetracycline hydrochloride (ANT); (3) basal diets $+1000 \mathrm{mg} / \mathrm{kg}$ probiotics (PRO); (4) basal diets $+500 \mathrm{mg} / \mathrm{kg}$ Achyranthes bidentata polysaccharides (ABSP); and (5) basal diets $+1000 \mathrm{mg} / \mathrm{kg}$ probiotics $+500 \mathrm{mg} / \mathrm{kg}$ Achyranthes bidentata polysaccharides (P-ABPS). Each dietary group had 6 pens $(1.4 \mathrm{~m} \times 2.0 \mathrm{~m})$, and 4 pigs (the same sex ratio) were included in each pen. All piglets were housed in a temperature-controlled $\left(28 \pm 2{ }^{\circ} \mathrm{C}\right)$ nursery room. The experimental period was 28 days, and pigs had free access to feed and water in the whole period. The piglets were fed their respective diets 4 times per day at 8:00 a.m., 11:00 a.m., 2:30 p.m. and 5:30 p.m., successively. The basal diets (Table 1) were formulated to meet or exceed the nutrient requirements for weaned pigs recommended by the NRC [9] and also comply with the practice of Chinese swine production. 
Table 1. The ingredient composition and nutrient levels of the basal diets (as-fed basis, \%).

\begin{tabular}{cc}
\hline Items & Contents \\
\hline Ingredients & 49.17 \\
Corn & 16.00 \\
Extruded corn & 18.00 \\
Soybean meal & 4.00 \\
Fermented soybean meal & 2.00 \\
Whey powder & 2.00 \\
Glucose & 1.00 \\
Fatty powder & 4.00 \\
Fish meal & 3.00 \\
Premix 1 & 0.50 \\
L-lysine HCl & 0.11 \\
DL-methionine & 0.20 \\
L-threonine & 0.02 \\
L-tryptophan & 100.00 \\
Total & \\
Calculated nutrient level & 3546 \\
Digestible energy, kcal/kg & 3352 \\
Metabolizable energy, kcal/kg & 18.61 \\
Crude protein & 1.23 \\
SID lysine & 0.36 \\
SID methionine & 0.73 \\
SID threonine & 0.20 \\
SID tryptophan & 3981 \\
Analysed nutrient level & 88.86 \\
Gross energy, kcal/kg & 18.78 \\
Dry matter & \\
Crude protein & \\
\hline Proving &
\end{tabular}

Note: ${ }^{1}$ Provided per kg of diet: 12,000 IU vitamin A, 2400 IU vitamin D3, 45 IU vitamin E, $3.0 \mathrm{mg}$ vitamin $\mathrm{K}$ $0.40 \mathrm{mg}$ vitamin B1, $6.4 \mathrm{mg}$ vitamin B2, $0.3 \mathrm{mg}$ vitamin B6, $36 \mu \mathrm{g}$ VB12, $2 \mathrm{mg}$ folic acid, $40 \mathrm{mg}$ nicotinic acid, $20 \mathrm{mg}$ D-pantothenic acid, $0.45 \mathrm{mg}$ biotin, $120 \mathrm{mg} \mathrm{Fe}, 6 \mathrm{mg} \mathrm{Cu}, 40 \mathrm{mg} \mathrm{Mn}, 100 \mathrm{mg} \mathrm{Zn}, 1.30 \mathrm{mg}$ I, $0.30 \mathrm{mg}$ Se.

\subsection{Growth Performance and Fecal Score}

Pig's body weights were measured at the beginning and end of the experimental period, and feed consumption was recorded on a pen basis during the experiment to calculate ADG, ADFI, and F/G. Fecal score was performed according to the method introduced by Lu et al. [10], and scoring criteria was showed as the following: hard feces $=1$; slightly soft $=2$; soft and partially formed feces $=3$; loose, semi-liquid $=4$; watery feces $=5$.

\subsection{Nutrient Digestibility}

During a 3-day (d 25-27) collection period, fecal samples from each pen were partially collected and transferred into plastic bags and stored at $-20^{\circ} \mathrm{C}$. Three-day fecal samples were separately thawed and pooled within pen and diet, homogenized and subsampled. Fecal subsamples were dried at $65{ }^{\circ} \mathrm{C}$ for $72 \mathrm{~h}$ in an air-forced oven. The diets and fecal samples were finely ground to pass through a 1-mm screen and analyzed using the AOAC [11] procedures for dry matter (DM, 930.15) and crude protein (CP, 984.13). The gross energy (GE) of samples were determined with an Oxygen Bomb Automatic Calorimeter (HXR-6000, Hunan Huaxing Energy Sources Instrument Co. Ltd., Changsha, China). The acid-insoluble ash (AIA) [12] was used as an internal indicator to calculate apparent total tract digestibility (ATTD) of DM, CP, and GE in diets fed to pigs.

\subsection{Serum Biochemical and Immune Indexes}

At the conclusion of the trial (d 29), one pig from each pen with similar BW was selected to collect blood from the anterior vena cava using $10 \mathrm{~mL}$ vacuum tubes. Blood samples $(5 \mathrm{~mL})$ were left alone for $30 \mathrm{~min}$, then centrifuged at $3000 \mathrm{r} / \mathrm{min}$ and $4{ }^{\circ} \mathrm{C}$ for $10 \mathrm{~min}$ to collect the serum, and stored at $-20^{\circ} \mathrm{C}$ for subsequent analysis. Serum 
total protein (TP), albumin (ALB), blood urea nitrogen (BUN), immune globulin A (IgA), immune globulin G (IgG), and immune globulin M (IgM) were analyzed using BS 200 Automatic Biochemical Analyzer (Mindray) with the relevant reagent kits and its instructions (Mindray).

\subsection{Serum and Intestinal Cytokines Mesured by Elisa Kit}

Serum interleukin-1 $\beta$ (IL-1 $\beta$ ), interleukin 2 (IL-2) and Tumor necrosis factor- $\alpha$ (TNF- $\alpha$ ) were determined by radio-immunoassays using kits purchased from Beijing Chemclin Biotech (Beijing, China) as described by Kong et al. [13].

After blood collection, pigs were humanely slaughtered by an intracardial injection of sodium pentobarbital at a dose of $50 \mathrm{mg} / \mathrm{kg} \mathrm{BW}$, then the intestinal tissues were isolated. The jejunal tissue was homogenated, centrifuged, and the supernatant was achieved to collect total protein. The protein concentrations were detected using a BCA protein assay kit (MERCK). The level of jejunal secretory IgA (sIgA) was determined in triplicate by an Elisa kit (Cusabio Biotech Co., Ltd., Wuhan, China) as described by Li et al. [14]. The unit was expressed as $\mu \mathrm{g} / \mathrm{mg}$ protein.

\subsection{Intestinal Morphology and Intraepithelial Lymphocyte}

After intestinal tissue separation, about $2 \mathrm{~cm}$ segments of duodenum, jejunum, and ileum were quickly snipped and flushed with sterile saline, fixed immediately in $4 \%$ paraformaldehyde solution and then embedded in paraffin. An approximate $5 \mu \mathrm{m}$ thickness section of each sample was stained with hematoxylin-eosin (HE) for intestinal morphology analysis. The count of the intestinal intraepithelial lymphocytes was measured using HistostainTM-Plus Kits (Beijing Zhongshan Golden Bridge Company, Beijing, China). For each intestinal tissue section, the number of intraepithelial lymphocytes together with the villus height $(\mathrm{VH})$ and crypt depth $(\mathrm{CD})$ were calculated using computer-assisted microscopy (DT2000, Panasonic, Osaka, Japan) and image-analysis software (Motic Images Plus 2.0, Dongguan, China).

\subsection{Statistical Analysis}

All statistical analyses were performed by one-way ANOVA using the GLM procedure of SPSS 17.0 (SPSS Inc., Chicago, IL, USA). Each pen acts as a statistical unit for growth performance and nutrients digestibility, whereas each pig as a statistical unit for serum chemical parameters, intestinal structure, and immune indexes. All results present as Mean \pm SEM. Difference among means were determined using Duncan's multiple range test. $p<0.05$ was considered statistically significant, while $0.05<p<0.10$ as a tendency.

\section{Results}

\subsection{Growth Performance and Fecal Score}

Pigs in ANT, PRO, and P-ABPS groups had greater $(p<0.05)$ final weight, ADG, and ADFI than those in the CON group (Table 2). Dietary supplementation with ANT and P-ABPS decreased $(p<0.05) \mathrm{F} / \mathrm{G}$ and fecal score compared with CON. However, no differences $(p>0.05)$ were observed in these response criteria among ANT, PRO, and P-ABPS groups. 
Table 2. Effects of probiotics and achyranthes bidentata polysaccharides on the growth performance of piglets (23-51 d).

\begin{tabular}{|c|c|c|c|c|c|c|c|}
\hline Items & $\mathrm{CON}^{1}$ & ANT $^{1}$ & PRO $^{1}$ & ABPS ${ }^{1}$ & P-ABPS ${ }^{1}$ & SEM & $p$-Value \\
\hline Initial Weight (kg) & 6.89 & 6.84 & 6.83 & 6.88 & 6.85 & 0.47 & 0.872 \\
\hline Final Weight (kg) & $13.71^{b}$ & $15.91^{\mathrm{a}}$ & $14.53^{\mathrm{a}}$ & $14.13^{\mathrm{ab}}$ & $15.47^{\mathrm{a}}$ & 2.31 & 0.045 \\
\hline $\operatorname{ADG}(\mathrm{g} / \mathrm{d})^{2}$ & $234.39^{c}$ & $323.72^{a}$ & $275.42^{a b}$ & $259.12^{b}$ & $308.20^{a}$ & 64.93 & 0.006 \\
\hline $\operatorname{ADFI}(g / d)^{2}$ & $418.27^{b}$ & $476.28^{a}$ & $451.39^{a b}$ & $429.94^{b}$ & $489.71^{\mathrm{a}}$ & 87.94 & 0.048 \\
\hline $\mathrm{F} / \mathrm{G}^{2}$ & $1.78^{\mathrm{a}}$ & $1.47^{\mathrm{b}}$ & $1.64^{\mathrm{ab}}$ & $1.66^{\mathrm{ab}}$ & $1.59^{b}$ & 0.14 & 0.031 \\
\hline Fecal score ${ }^{2}$ & $3.47^{\mathrm{a}}$ & $2.78^{b}$ & $2.84^{\mathrm{b}}$ & $2.82^{b}$ & $2.65^{b}$ & 0.57 & 0.025 \\
\hline
\end{tabular}

Note: ${ }^{1} \mathrm{CON}$, basal diets; ANT, basal diets + antibiotics; PRO, basal diets + probiotics; ABSP, basal diets + Achyranthes bidentata polysaccharides; P-ABPS: basal diets + probiotics + Achyranthes bidentata polysaccharides. ${ }^{2}$ ADG, average daily weight; ADFI, average daily feed intake; F/G, feed/gain; Fecal score: hard feces = 1; slightly soft = 2; soft and partially formed feces $=3$; loose, semi-liquid = 4; watery feces $=5$. ${ }^{a, b, c}$ Mean values with different superscripts in the same row differ significantly $(p<0.05)$. SEM is standard error of mean. $n=6$ means data come from six pens per dietary treatment.

\subsection{Nutrient Digestibility}

Compared with CON, ANT, PRO, ABPS, and P-ABPS improved $(p<0.05)$ apparent total tract digestibility (ATTD) of CP and GE in diets fed to weaned pigs (Table 3 ). However, there were no differences $(p>0.05)$ among ANT, PRO, ABPS, and P-ABPS treatments.

Table 3. Effects of probiotics and Achyranthes bidentata polysaccharides on apparent total tract digestibility (ATTD) of diet fed to piglets.

\begin{tabular}{cccccccc}
\hline Items & CON $^{\mathbf{1}}$ & ANT $^{\mathbf{1}}$ & PRO $^{\mathbf{1}}$ & ABPS $^{\mathbf{1}}$ & P-ABPS $^{\mathbf{1}}$ & SEM & -Value \\
\hline Dry matter & 88.27 & 89.33 & 88.82 & 88.73 & 89.11 & 1.24 & 0.231 \\
Crude protein & $78.40^{\mathrm{b}}$ & $82.44^{\mathrm{a}}$ & $82.36^{\mathrm{a}}$ & $82.27^{\mathrm{a}}$ & $82.39^{\mathrm{a}}$ & 2.31 & 0.032 \\
Gross energy & $85.52^{\mathrm{b}}$ & $87.54^{\mathrm{a}}$ & $87.36^{\mathrm{a}}$ & $87.27^{\mathrm{a}}$ & $87.27^{\mathrm{a}}$ & 0.49 & 0.027 \\
\hline
\end{tabular}

Note: ${ }^{1} \mathrm{CON}$, basal diets; ANT, basal diets + antibiotics; PRO, basal diets + probiotics; ABSP, basal diets + Achyranthes bidentata polysaccharides; P-ABPS: basal diets + probiotics + Achyranthes bidentata polysaccharides. ${ }^{\mathrm{a}, \mathrm{b}}$ Mean values with different superscripts in the same row differ significantly $(p<0.05)$. SEM is standard error of mean. $n=6$ means data come from six pens per dietary treatment.

\subsection{Serum Biochemical and Immune Parameters and Cytokines}

Serum TP in the P-ABPS group was higher than in the CON group $(p<0.05)$, but no differences were found compared with the remaining groups (Table 4). Pigs in the ANT, PRO, ABPS, and P-ABPS groups had greater $(p<0.05)$ serum albumin contents, but lower $(p<0.05)$ serum blood urea nitrogen (BUN) and interleukin-1 $\beta$ (IL-1 $\beta$ ) contents than the CON group. Serum immune globulin A (IgA) and interleukin-2 (IL-2) concentrations were higher $(p<0.05)$ in pigs fed the ANT, ABPS, and P-ABPS supplemented diet in comparison with the CON diet.

Table 4. Effects of probiotics and Achyranthes bidentata polysaccharides on serum biochemical and immune indexes, and cytokines of piglets.

\begin{tabular}{|c|c|c|c|c|c|c|c|}
\hline Items & $\mathrm{CON}^{1}$ & ANT $^{1}$ & PRO $^{1}$ & ABPS $^{1}$ & P-ABPS ${ }^{1}$ & SEM & $p$-Value \\
\hline Total protein $(\mathrm{g} / \mathrm{L})$ & $46.75^{\mathrm{b}}$ & $51.10^{\mathrm{ab}}$ & $52.70^{\mathrm{ab}}$ & $55.15^{a b}$ & $59.50^{a}$ & 5.30 & 0.037 \\
\hline Albumin $(\mathrm{g} / \mathrm{L})$ & $23.98^{b}$ & $31.09^{\mathrm{a}}$ & $29.51^{\mathrm{a}}$ & $29.77^{\mathrm{a}}$ & $28.39^{a}$ & 2.17 & 0.019 \\
\hline Blood urea nitrogen $(\mathrm{mmol} / \mathrm{L})$ & $4.60^{\mathrm{a}}$ & $3.74^{\mathrm{b}}$ & $3.53^{b}$ & $3.62^{b}$ & $3.71^{b}$ & 0.84 & 0.031 \\
\hline Immune globulin $\mathrm{A}(\mathrm{g} / \mathrm{L})$ & $0.84^{b}$ & $0.97^{\mathrm{a}}$ & $0.88^{a b}$ & $1.05^{\mathrm{a}}$ & $1.12^{\mathrm{a}}$ & 0.22 & 0.016 \\
\hline Immune globulin $\mathrm{M}(\mathrm{g} / \mathrm{L})$ & 0.53 & 0.84 & 0.70 & 0.76 & 0.87 & 0.16 & 0.238 \\
\hline Immune globulin $\mathrm{G}(\mathrm{g} / \mathrm{L})$ & 0.98 & 1.08 & 1.12 & 1.16 & 1.2 & 0.20 & 0.192 \\
\hline Interleukin-2(ng/mL) & $2.37^{\mathrm{b}}$ & $4.97^{\mathrm{a}}$ & $3.45^{\mathrm{ab}}$ & $3.79^{a}$ & $5.35^{\mathrm{a}}$ & 0.94 & 0.049 \\
\hline Interleukin- $1 \beta(\mathrm{ng} / \mathrm{mL})$ & $0.27^{\mathrm{a}}$ & $0.21^{\mathrm{b}}$ & $0.19^{b}$ & $0.17^{b}$ & $0.18^{b}$ & 0.03 & 0.031 \\
\hline $\begin{array}{l}\text { Tumor necrosis } \\
\text { factor- } \alpha(\mathrm{ng} / \mathrm{mL})\end{array}$ & 0.51 & 0.49 & 0.52 & 0.46 & 0.47 & 0.07 & 0.107 \\
\hline
\end{tabular}

Note: ${ }^{1}$ CON, basal diets; ANT, basal diets + antibiotics; PRO, basal diets + probiotics; ABSP, basal diets + Achyranthes bidentata polysaccharides; P-ABPS: basal diets + probiotics + Achyranthes bidentata polysaccharides. ${ }^{\mathrm{a}, \mathrm{b}}$ Mean values with different superscripts in the same row differ significantly $(p<0.05)$. SEM is standard error of mean. $n=6$ means data come from six pigs per dietary treatment. 


\subsection{Intestinal Morphology and Immune Function}

Compared with the CON and ANT groups, jejunal villus height $(\mathrm{VH})$ in ABPS and P-ABPS was improved $(p<0.05)$, and ileal VH in PRO, ABPS, and P-ABPS groups had a trend to increase $(p=0.081)$ (Table 5$)$. Intraepithelial lymphocyte in duodenum was greater $(p<0.05)$ in ANT, PRO, ABPS, and P-ABPS group than in CON group. Dietary P-ABPS improved $(p<0.05)$ intraepithelial lymphocyte in jejunum and ileum in comparison with the CON diet. Additionally, sIgA in the jejunal mucosa of pigs fed ANT, ABPS, and P-ABPS diets was greater $(p<0.05)$ than the CON diets (Figure 1$)$.

Table 5. Effects of probiotics and Achyranthes bidentata polysaccharides on small intestinal morphology and intraepithelial lymphocyte in piglets.

\begin{tabular}{|c|c|c|c|c|c|c|c|}
\hline Items & $\mathrm{CON}^{1}$ & ANT $^{1}$ & PRO $^{1}$ & ABPS ${ }^{1}$ & P-ABPS ${ }^{1}$ & SEM & $p$-Value \\
\hline \multicolumn{8}{|l|}{ Duodenum } \\
\hline Villus height & 412.37 & 408.42 & 415.17 & 423.29 & 419.34 & 8.81 & 0.221 \\
\hline Crypt depth & 173.07 & 169.11 & 171.45 & 181.22 & 177.09 & 4.80 & 0.429 \\
\hline VH/CD & 2.38 & 2.42 & 2.42 & 2.34 & 2.37 & 0.04 & 0.141 \\
\hline $\begin{array}{c}\text { Intraepithelial lymphocyte } \\
\text { Jejunum }\end{array}$ & $39.67^{c}$ & $83.00^{\mathrm{b}}$ & $93.67^{\mathrm{a}}$ & $90.00^{\mathrm{a}}$ & $95.33^{\mathrm{a}}$ & 17.85 & 0.009 \\
\hline Villus height & $387.21^{b}$ & $385.07^{b}$ & $390.19^{a b}$ & $397.92^{a}$ & $394.83^{a}$ & 5.31 & 0.034 \\
\hline Crypt depth & 139.41 & 137.34 & 141.15 & 146.96 & 144.13 & 3.81 & 0.262 \\
\hline $\mathrm{VH} / \mathrm{CD}$ & 2.78 & 2.80 & 2.76 & 2.71 & 2.74 & 0.04 & 0.901 \\
\hline $\begin{array}{l}\text { Intraepithelial lymphocyte } \\
\text { Ileum }\end{array}$ & $48.75^{b}$ & $79.30 \mathrm{ab}$ & $88.30^{a b}$ & $81.70 \mathrm{ab}$ & $94.64^{\mathrm{a}}$ & 19.44 & 0.013 \\
\hline Villus height & $322.52^{b}$ & $328.33^{b}$ & $345.00^{a}$ & $337.74^{\mathrm{a}}$ & $341.51^{\mathrm{a}}$ & 9.36 & 0.081 \\
\hline Crypt depth & 120.54 & 119.27 & 126.38 & 120.09 & 128.10 & 4.06 & 0.462 \\
\hline $\mathrm{VH} / \mathrm{CD}$ & 2.68 & 2.75 & 2.73 & 2.81 & 2.67 & 0.06 & 0.561 \\
\hline Intraepithelial lymphocyte & $67.27^{b}$ & $86.41^{\mathrm{ab}}$ & $91.32^{a b}$ & $89.20^{a b}$ & $94.16^{\mathrm{a}}$ & 9.12 & 0.032 \\
\hline
\end{tabular}

Note: ${ }^{1} \mathrm{CON}$, basal diets; ANT, basal diets + antibiotics; PRO, basal diets + probiotics; ABSP, basal diets + Achyranthes bidentata polysaccharides; P-ABPS: basal diets + probiotics + Achyranthes bidentata polysaccharides. ${ }^{a, b, c}$ Mean values with different superscripts in the same row differ significantly $(p<0.05)$. SEM is standard error of mean. $n=6$ means data come from six pigs per dietary treatment.

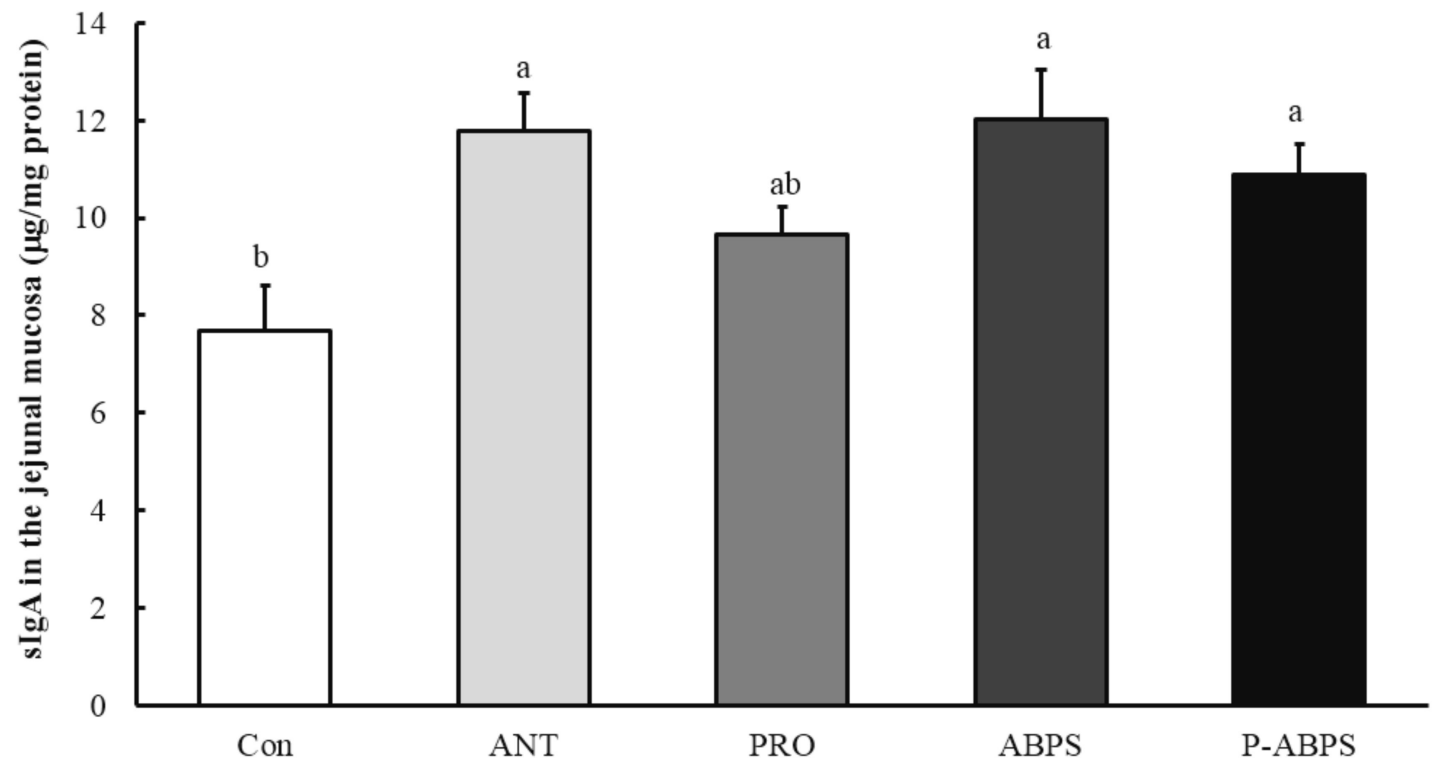

Figure 1. Levels of secreted immunoglobulin A (sIgA) in the jejunal mucosa. CON, basal diets; ANT, basal diets + antibiotics; PRO, basal diets + probiotics; ABSP, basal diets + Achyranthes bidentata polysaccharides; P-ABPS: basal diets + probiotics + Achyranthes bidentata polysaccharides. Different letters $(a, b)$ above the error bars indicated significant differences $(p<0.05)$. $n=6$ means data come from six pigs per dietary treatment. 


\section{Discussion}

Piglets after weaning exhibit impaired or retarded growth performance and their gastrointestinal tract are susceptible to pathogens, which may easily cause post-weaning diarrhea [10,15]. In-feed antibiotics' supplementation can effectively solve these difficulties. In our study, compared with the CON group, pigs in the ANT group had greater ADG and ADFI, and lower F/G and fecal score; meanwhile, dietary PRO, ABPS, or P-ABPS supplementation showed a similar beneficial role on piglet growth performance as ANT. Probiotics are considered to be an alternative to in-feed antibioics and can promote piglet growth through favoring nutrient digestion, modulating the gastrointestinal ecosystem, stimulating the immune system, and protecting the host from gastrointestinal tract diseases [16-18]. However, some studies showed that there was no significant role for piglet growth performance in response to probiotics supplementation [19], which might be attributed to the viable counts of probiotics ingested in feed and colonized in the intestine. Just as it is defined by the World Health organization (WHO) as "microorganisms, which administering live and adequate amounts, confers a benefit to the health of the host" [20]. ABPS as a traditional Chinese medicine has also been used in pig production, and previous studies both in vitro and in vivo revealed that ABPS improved weaned pig growth performance mainly through enhancing cellular and humoral immune responses to perform an important protective role in the non-specific defense against infections [6,7]. Interestingly, probiotics in combination with ABPS used in the present study showed a better beneficial effect on the piglet growth than probiotics or ABPS used alone, which was line with our expectations and suggest the existence of an interaction of the combined use of the two products.

Feed is the primary source of energy and protein for animal maintenance and growth requirements $[21,22]$. The digested and absorbed nutrients by the gastrointestinal tract provide energy and amino acids for animal life activities and growth via biological oxidation and metabolism [23,24]. In our study, dietary ANT, PRO, ABPS, and P-ABPS supplementation increased ATTD of GE and CP in diets fed to piglets, demonstrating that these products promoted gastrointestinal digestion and absorption, enhancing the nutrients' utilization efficiency, which is an evidence for improving piglet growth performance. The improvement of nutrient utilization was chiefly associated with reducing nutrient consumption of intestinal bacteria by in-feed antibiotics [25], producing organic acids and digestive enzymes by probiotics [17], and improving intestinal immune function by ABPS [6,7].

The fluctuation of serum biochemical indexes can reflect the body metabolism and health. The levels of serum TP, ALB, and BUN are strongly linked to protein digestion and absorption, especially serum BUN, which is the main end product of protein metabolism in mammals [26]. In our study, dietary ANT, PRO, ABPS, and P-ABPS addition increased the content of serum ALB but decreased the serum BUN content, indicating that protein utilization in these dietary treatments was improved, which echoed the improved ATTD of $\mathrm{CP}$ and $\mathrm{ADG}$ aforementioned. $\operatorname{Ig} \mathrm{A}, \mathrm{IgG}$, and IgM are generated by bone marrow-derived B lymphocytes, which can mediate humoral immunity and serve as important response criteria to evaluate humoral immune response in humans and animals [27]. In the present study, pigs in the ANT, ABPS, and P-ABPS groups had greater serum IgA content than those in the CON group, indicating that pigs' humoral immunity were boosted in response to these products' supplementation, which concurred with the previous reports $[5-7,28]$. Furthermore, the increased protein utilization by adding these products could provide substrates for immunoglobulin synthesis, which could partly offer interpretation for the improvement of immunity.

The gastrointestinal tract is the place for digestion and absorption of nutrients, maintaining its morphological structure is of great importance for gut health. However, anorexia or low feed intake after weaning appears, which means lack of supply of luminal nutrition, and challenges and stressors associated with weaning also cause changes to the structure and function of the gastrointestinal tract [28]. In our study, pigs in the CON group had 
lower ADFI and villus height in the jejunum and ileum compared with pigs in P-ABPS groups, indicating that a dietary P-ABPS played a role in maintaining intestinal structure and function, which might be related to regulation of microflora by probiotics and improvement of mucosal structure and function by ABPS $[6,7,28]$. The weaning transition not only results in marked structural and functional changes to the small intestine, but also contributes to an intestinal inflammatory status that in turn compromises villouscrypt architecture, gastrointestinal tract barrier function, and disruption of the microbiota [10,28]. IL-1 $\beta$ and TNF- $\alpha$, proinflammatory cytokine, are produced by mononuclear macrophages, which can reflect the body inflammatory condition. IL-2 is a chemotactic factor and mainly generated by activated T cells, which can promote growth, proliferation, and differentiation of lymphocytes to participate in humoral immune response [29,30]. In our study, pigs in the CON group had greater serum IL-1 $\beta$ and lower IL-2 than pigs in the other groups, suggesting that adding ANT, PRO, ABPS, and P-ABPS to the diet could alleviate inflammatory response induced by weaning.

The gastrointestinal tract is the largest immune organ and its superficial mucosa serve as the first line of defense against pathogen invasion. sIgA is the main antibody present on mucosal surfaces, which have long been considered as a first line of defense via providing passive immunoprotection against invading antigens and can protect the intestinal epithelium from enteric pathogens and toxins [14,31]. Meanwhile, intraepithelial lymphocytes (IEL) reside within the epithelial layer of mucosal and barrier tissues and represent the first immune system cells to encounter pathogens that have invaded an epithelial surface [32]. In the present study, dietary P-ABPS supplementation increased the levels of sIgA in the jejunal mucosa and intraepithelial lymphocytes in the small intestine, indicating that dietary PRO combined with ABPS could enhance intestinal immune function.

\section{Conclusions}

Dietary PRO or ABPS used alone or in combination (P-ABPS) could improve piglets' growth performance via promoting intestinal nutrient digestion and absorption and enhancing immune function, indicating that PRO, ABPS, or P-ABPS have the potential to replace in-feed antibiotics in piglet diets, and the combined effect of probiotics and ABPS is comparable to in-feed antibiotics.

Author Contributions: Conceptualization, R.L. and G.H.; investigation, G.H., W.P. and L.W.; resources, X.H.; data curation, G.H.; writing—original draft preparation, G.H. and R.L.; writingreview and editing, X.H. and Y.Y.; project administration, R.L. and X.H.; funding acquisition, Y.Y. and R.L. All authors have read and agreed to the published version of the manuscript.

Funding: This research was funded by the Science and Technology Innovation Program of Hunan Province (2020RC2063) and the Open Fund of Key Laboratory of Agro-Ecological Processes in Subtropical Region, Chinese Academy of Sciences (ISA2021103).

Institutional Review Board Statement: The study was conducted according to the guidelines of the Declaration of Helsinki, and approved by the Institutional Review Board (or Ethics Committee) of the Animal Care and Use Committee of the Institute of Subtropical Agriculture, Chinese Academy of Sciences (IACUC\#201302).

Data Availability Statement: All data are included in the article.

Conflicts of Interest: The authors declare no conflict of interest.

\section{References}

1. Gresse, R.; Chaucheyras-Durand, F.; Fleury, M.A.; Van de Wiele, T.; Forano, E.; Blanquet-Diot, S. Gut microbiota dysbiosis in postweaning piglets: Understanding the keys to health. Trends Microbiol. 2017, 25, 851-873. [CrossRef]

2. Wang, Y.; Xie, Q.; Sun, S.; Huang, B.; Zhang, Y.; Xu, Y.; Zhang, S.; Xiang, H. Probiotics-fermented massa medicata fermentata ameliorates weaning stress in piglets related to improving intestinal homeostasis. Appl. Microbiol Biot. 2018, 102, 10713-10727. [CrossRef] 
3. Diana, A.; Manzanilla, E.G.; Calderon Diaz, J.A.; Leonard, F.C.; Boyle, L.A. Correction: Do weaner pigs need in-feed antibiotics to ensure good health and welfare? PLoS ONE 2017, 12, e0189434. [CrossRef] [PubMed]

4. Herich, R.; Revajova, V.M.; Bomba, A.; Nemcova, R.; Guba, P. The effect of Lactobacillus paracasei and Raftilose P95 upon the non-specific immune response of piglets. Food Agric. Immunol. 2002, 14, 171-179. [CrossRef]

5. Hou, C.; Zeng, X.; Yang, F.; Liu, H.; Qiao, S. Study and use of the probiotic Lactobacillus reuteri in pigs: A review. J. Anim. Sci. Biotechnol. 2016, 6, 14. [CrossRef] [PubMed]

6. Chen, Q.; Liu, Z.; He, J.H. Achyranthes bidentata polysaccharide enhances immune response in weaned piglets. Immunopharm. Immunot. 2009, 31, 253-260. [CrossRef] [PubMed]

7. Chen, Q.; Liu, Z.; He, J.; Zhao, Y.; Wu, X. Achyranthes bidentata polysaccharide enhances growth performance and health status in weaned piglets. Food Agric. Immunol. 2011, 22, 17-29. [CrossRef]

8. Huang, X.G.; He, J.H.; Yang, C.J.; Li, Z.J.; Huang, H.; Wen, L.X. A Prepartion Method for Probiotics. U.S. Patent CN101138392, 12 March 2008. (In Chinese).

9. National Research Council. Nutrient Requirements of Swine, 11th ed.; National Academic Press: Washington, DC, USA, 2012.

10. Lu, X.; Zhang, M.; Zhao, L.; Ge, K.; Wang, Z.; Jun, L.; Ren, F. Growth performance and post-weaning diarrhoea in piglets fed a diet supplemented with probiotic complexes. J. Microbiol. Biotechnol. 2018, 28, 1791-1799. [CrossRef]

11. AOAC. Official Methods of Analysis, 18th ed.; Association of Official Analytical Chemists International: Gaithersburg, MD, USA, 2006.

12. Brestensk, M.; Nitrayová, S.; Heger, J.; Patrá, P. Chromic oxide and acid-insoluble ash as markers in digestibility studies with growing pigs and sows. J. Anim. Physiol. Anim. Nutr. 2017, 101, 46-52. [CrossRef] [PubMed]

13. Kong, X.F.; Yin, Y.L.; Wu, G.Y.; Liu, H.J.; Yin, F.G.; Li, T.J.; Huang, R.L.; Ruan, Z.; Xiong, H.; Deng, Z.Y.; et al. Dietary supplementation with Acanthopanax senticosus extract modulates cellular and humoral immunity in weaned piglets. Asian Australas. J. Anim. Sci. 2007, 20, 1453-1461. [CrossRef]

14. Li, R.; Song, Z.; Zhao, J.; Huo, D.; Fan, Z.; Hou, D.X.; He, X. Dietary L-theanine alleviated lipopolysaccharide-induced immunological stress in yellow-feathered broilers. Anim. Nutr. 2018, 4, 265-272. [CrossRef]

15. Heo, J.M.; Opapeju, F.O.; Pluske, J.R.; Kim, J.C.; Hampson, D.J.; Nyachoti, C.M. Gastrointestinal health and function in weaned pigs: A review of feeding strategies to control post-weaning diarrhoea without using in-feed antimicrobial compounds. J. Anim. Physiol. Anim. Nutr. (Berl.) 2013, 97, 207-237. [CrossRef]

16. Gaggia, F.; Mattarelli, P.; Biavati, B. Probiotics and prebiotics in animal feeding for safe food production. Int. J. Food Microbiol. 2010, 141 (Suppl. 1), S15-S28. [CrossRef]

17. Liao, S.F.; Nyachoti, C.M. Using probiotics to improve swine gut health and nutrient utilization. Anim. Nutr. 2017, 3, 331-343. [CrossRef] [PubMed]

18. Long, S.; He, T.; Kim, S.W.; Shang, Q.; Kiros, T.; Mahfuz, S.U.; Wang, C.; Piao, X. Live yeast or live yeast combined with zinc oxide enhanced growth performance, antioxidative capacity, immunoglobulins and gut health in nursery pigs. Animals 2021, 11, 1626. [CrossRef] [PubMed]

19. Guerra-Ordaz, A.A.; Molist, F.; Hermes, R.G.; Segura, A.G.D.; Ragione, R.M.L.; Woodward, M.J.; Tchorzewska, M.A.; Collins, J.W.; Pérez, J.F.; Martín-Orúe, S.M. Effect of inclusion of lactulose and Lactobacillus plantarum on the intestinal environment and performance of piglets at weaning. Anim. Feed Sci. Technol. 2013, 185, 160-168. [CrossRef]

20. Cheng, G.; Hao, H.; Xie, S.; Wang, X.; Dai, M.; Huang, L.; Yuan, Z. Antibiotic alternatives: The substitution of antibiotics in animal husbandry? Front. Microbiol. 2014, 5, 217. [CrossRef] [PubMed]

21. Kong, C.; Adeola, O. Evaluation of amino Acid and energy utilization in feedstuff for Swine and poultry diets. Asian Australas. J. Anim. Sci. 2014, 27, 917-925. [CrossRef]

22. Li, R.; Hou, G.F.; Song, Z.H.; Zhao, J.F.; Fan, Z.Y.; Hou, D.X.; He, X. Nutritional value of enzyme-treated soybean meal, concentrated degossypolized cottonseed protein, dried porcine solubles and fish meal for $10-$ to- $20 \mathrm{~kg}$ pigs. Anim. Feed. Sci. Tech. 2019, 252, 23-33. [CrossRef]

23. Chwalibog, A.; Tauson, A.H.; Thorbek, G. Energy metabolism and substrate oxidation in pigs during feeding, starvation and re-feeding. J. Anim. Physiol. Anim. Nutr. (Berl.) 2004, 88, 101-112. [CrossRef] [PubMed]

24. Li, R.; Hou, G.; Song, Z.; Wu, C.; Zhao, J.; Sun, X.; Xiang, X.; Fan, Z.; Hou, D.X.; He, X. Effects of different protein sources completely replacing fish meal in low-protein diet on growth performance, intestinal digestive physiology, and nitrogen digestion and metabolism in nursery pigs. Anim. Sci. J. 2019, 90, 977-989. [CrossRef] [PubMed]

25. Allen, H.K.; Levine, U.Y.; Torey, L.; Meggan, B.; Casey, T.A. Treatment, promotion, commotion: Antibiotic alternatives in food-producing animals. Trends Microbiol. 2013, 21, 114-119. [CrossRef] [PubMed]

26. Whang, K.Y.; Easter, R.A. Blood urea nitrogen as an index of feed efficiency and lean growth potential in growing-finishing swine. Asian Australas. J. Anim. Sci. 2000, 13, 811-816. [CrossRef]

27. Li, R.; Hou, G.F.; Huang, Q.Y.; Peng, W.; Shi, Y.J.; Liu, T.; Gong, Y.; Gao, H.; Huang, X.G. Effects of lactobacillus delbrueckii on growth performance, serum biochemical parameters, immune and antioxidant function in suckling piglets. Chinese J. Anim. Nutr. 2013, 25, 2943-2950. (In Chinese)

28. Pluske, J.R.; Turpin, D.L.; Kim, J.C. Gastrointestinal tract (gut) health in the young pig. Anim. Nutr. 2018, 4, 187-196. [CrossRef]

29. Yang, Y.; Chen, J.; Li, H.; Wang, Y.; Xie, Z.; Wu, M.; Zhang, H.; Zhao, Z.; Chen, Q.; Fu, M.; et al. Porcine interleukin-2 gene encapsulated in chitosan nanoparticles enhances immune response of mice to piglet paratyphoid vaccine. Comp. Immunol. Microbiol. Infect. Dis. 2007, 30, 19-32. [CrossRef] 
30. Pol, J.G.; Caudana, P.; Paillet, J.; Piaggio, E.; Kroemer, G. Effects of interleukin-2 in immunostimulation and immunosuppression. J. Exp. Med. 2020, 217, e20191247. [CrossRef]

31. Li, R.; Hou, G.; Jiang, X.; Song, Z.; Fan, Z.; Hou, D.X.; He, X. Different dietary protein sources in low protein diets regulate colonic microbiota and barrier function in a piglet model. Food Funct. 2019, 10, 6417-6428. [CrossRef]

32. Hoytema van Konijnenburg, D.P.; Mucida, D. Intraepithelial lymphocytes. Curr. Biol. 2017, 27, R737-R739. [CrossRef] 